\title{
Association of stem cell marker expression pattern and survival in human biliary tract cancer
}

\author{
RALF KEMMERLING $^{1 *}$, BEATE ALINGER $^{1 *}$, OTTO DIETZE $^{1}$, HANS-CHRISTIAN BÖSMÜLLER $^{4}$, \\ MATTHIAS OCKER ${ }^{3}$, GERNOT W. WOLKERSDÖRFER ${ }^{2}$, FRIEDER BERR ${ }^{2}$, \\ DANIEL NEUREITER ${ }^{1 * *}$ and TOBIAS KIESSLICH ${ }^{1,2^{* *}}$ \\ ${ }^{1}$ Institute of Pathology, ${ }^{2}$ Department of Internal Medicine I, Paracelsus Medical University, \\ Salzburger Landeskliniken (SALK), 5020 Salzburg, Austria; ${ }^{3}$ Institute for Surgical Research, \\ Philipps-University Marburg, 35043 Marburg, Germany; ${ }^{4}$ Institute of Pathology, \\ Krankenhaus Barmherzige Schwestern Linz, 4020 Linz, Austria
}

Received January 17, 2012; Accepted March 13, 2012

DOI: 10.3892/ijo.2012.1477

\begin{abstract}
The aim of this study was to investigate the molecular and protein expression pattern of markers of stemness phenotype and its clinicopathological significance in human biliary tract cancer (BTC). Human BTC cell lines (CCLP-1, Egi-1, MzChA-1, MzChA-2, SkChA-1, TFK-1 and $\mathrm{GBC}$ ) were analyzed in vitro and in xenotransplanted animals for expression of markers of stemness and compared to tissue microarrays (TMA) of 34 cases of human BTC with complete pathomorphological and clinical data (survival). Molecular analyses on the mRNA and protein level included makers of stemness and progenitor (Bmi-1, Sox-2, Nestin, CD133, CD44 and Nanog), proliferation and differentiation (cell cycle proteins, intermediate filaments). The investigated BTC samples showed a low to moderate and partially significantly different expression pattern of the stem cell markers in vitro, in vivo and in TMA. Hierarchical cluster analysis identified subgroups with homogenous expression of stem cell markers significantly differing with respect to cytokeratin expression in xenografts and Ki67 proliferation marker in human
\end{abstract}

Correspondence to: Dr Daniel Neureiter, Institute of Pathology, Paracelsus Medical University / Salzburger Landeskliniken (SALK), Müllner Hauptstrasse 48, 5020 Salzburg, Austria

E-mail:d.neureiter@salk.at

${ }^{*}$ Contributed equally

${ }^{* *}$ Senior authors

Abbreviations: ALDH, aldehyde dehydrogenase; BTC, biliary tract cancer; CI, confidence interval; FBS, fetal bovine serum; LSD, least significant difference; qRT-PCR, quantitative real-time reverse transcription PCR; SD, standard deviation; TMA, tissue microarray; WR, whipple resection

Key words: human biliary tract cancer, xenografts, stem cell marker, prognosis
TMA, respectively - thus indicating possible heterogeneous carcinogenesis pathways in BTC. Additionally, these stem cell markers could be linked to morphology and molecular markers of proliferation and differentiation on the mRNA and protein level. Finally, survival analysis identified the combination of CD133 and CD44 as an independent prognostic factor yet their value as prognostic factors need testing in prospective study design.

\section{Introduction}

Biliary tract cancers (BTC) comprise tumors of the extra- and intrahepatic bile ducts and the gallbladder cancer (1). The prognosis is poor as the only curative treatment, resection, is feasible in about $50 \%$ of patients only due to advanced stage and co-morbidities precluding surgery (2). Additionally, the 5-year survival rate is $13-44 \%$ only, even with optimal conditions of tumor cell-free margins and absence of lymph node dissemination (3). For non-resectable BTC, palliation using chemo- radio-chemotherapy or photodynamic tumor ablation could achieve median survival times of up to 18-28 months (4-6). As yet these therapies cannot stop BTC tumor cell proliferation in the long-term. Therefore, the identification of molecular mechanisms of tumor growth, of tumorigenic sub-populations of cells and of predictors of therapeutic response is needed to develop better strategies for treatment of BTC $(7,8)$.

In this context, it was recently proposed that cancer cells achieve a malignant phenotype by re-activating early embryonic differentiation programs that physiologically regulate invasion, migration, angiogenesis and differentiation, thus adopting characteristics of normal stem cells (9-11). Particularly the re-expression of embryonic transcriptions factors like c-Myc, Sox-2, Oct3/4, KLF4 or Nanog is now considered as a mediator of oncogenesis in solid tumors $(11,12)$.

The identification of cell surface markers expressed on tumor initiating cell populations (e.g. CD24, CD44) (13-15) has led to the description of so called stem cell-like signatures in various human cancers, including hepatocellular carcinoma 
Table I. Primer sequences for qRT-PCR and antibodies for IHC.

A, Primer sequences for real-time RT-PCR.

\begin{tabular}{llc}
\hline Transcript & \multicolumn{1}{c}{ Primer (forward / reverse) } & Amplicon [bp] \\
\hline$\beta$-Actin & ATCTTCACGGTGCTGGGCATTG / TCCTGTGTCCTGGCGGTTGACT & 206 \\
Bmi-1 & GCTAAATCCCCACCTGATGTGTGTG / TGGTCTGGTCTTGTGAACTTGGACAT & 163 \\
CD133 & GAACTCTCTTGAATGAAACTCCAGAGCA / GGTCTCCTTGATCGCTGTTGCC & 194 \\
CD44 & CCCAAATTCCAGAATGGCTGATC / GACGACTCCTTGTTCACCAAATGC & 220 \\
Nanog & GCCGAAGAATAGCAATGGTGTGAC / GACTGGATGTTCTGGGTCTGGTTG & 171 \\
Nestin & GGCAGCGTTGGAACAGAGGTT / GGCTGAGGGACATCTTGAGGTG & 170 \\
Sox-2 & GCACAACTCGGAGATCAGCAAGC / GGCAGCGTGTACTTATCCTTCTTCATG & 186 \\
\hline
\end{tabular}

B, Antibodies and conditions used for IHC.

\begin{tabular}{|c|c|c|c|c|}
\hline Antibody & Cat.-No. & Species & Dilution/incubation & Pretreatment ${ }^{\mathrm{c}}$ \\
\hline Bmi-1 & ab14389 & Mouse & $1: 100 / 1 / 2 h$ & Pascal / pH 6.0 \\
\hline CD133 & ab19898 & Rabbit & $1: 200 / 1 / 2 \mathrm{~h}$ & $\mathrm{WB} / \mathrm{pH} 9.0$ \\
\hline CD44 & NCL-CD44-2 $2^{\mathrm{b}}$ & Mouse & $1: 100 / 1 / 2 h$ & $\mathrm{WB} / \mathrm{pH} 9.0$ \\
\hline Nanog & $a b 21603^{a}$ & Rabbit & $1: 100 / 1 / 2 h$ & Pascal / pH 6.0 \\
\hline Nestin & $a b 22035^{a}$ & Mouse & $1: 200 / 1 / 2 h$ & WB / pH 9.0 \\
\hline Sox2 & ab97959 ${ }^{\mathrm{a}}$ & Rabbit & $1: 1,000 / 1 / 2 \mathrm{~h}$ & WB / pH 9.0 \\
\hline
\end{tabular}

${ }^{\text {aP }}$ urchased from Abcam plc, Cambridge, UK; ${ }^{b}$ purchased from Novocastra/Leica Mikrosysteme, Vienna, Austria; ${ }^{\mathrm{p}} \mathrm{pH}$ 9.0: heat-induced epitope retrieval in pH 9.0 antigen retrieval buffer (Dako, Glostrup, Denmark) and waterbath (WB); Pascal, pressurized heating chamber (Dako).

$\left[\mathrm{CD} 44^{+}, \mathrm{CD}^{+}, \mathrm{CD} 133^{+}, \mathrm{ALDH}\right.$ (aldehyde dehydrogenase)], neuroblastomas $\left(\mathrm{Oct}_{3}{ }^{+}, \mathrm{Sox}-2^{+}, \mathrm{Nanog}^{+}, \mathrm{KLF}^{+}\right)$and other disease entities (15). Although these markers are neither specific for a certain cancer histology nor for all stem cells per se, these profiles are independently associated with a poorer outcome in patients with e.g. colorectal cancer (16) and, in part, also in BTC (17). Yet, a detailed analysis of stem cell markers in BTC is still missing and only recently cells with stem cell-like properties (such as CD24 $4^{+}, \mathrm{CD}_{4} 4^{+}, \mathrm{EpCAM}^{+}$) were isolated from extrahepatic BTC (18). In line with these results, an aggressive phenotype was observed in BTC cells subsequent to overexpression of the stem cell-like genes c-MYC, Sox-2, OCT3/4, and KLF4 (19).

In this study, we investigated the expression of markers of putative stem- or progenitor cells in several human biliary tract cancer cell lines in vitro, in a nude mouse xenograft model in vivo and in a human TMA and correlated these expression patterns with cell proliferation and histological differentiation as well as clinicopathological characteristics.

\section{Materials and methods}

Cell culture and human BTC model. Bile duct carcinoma cell lines CCLP-1, Egi-1, SkChA-1, TFK-1 and gallbladder cancer cell lines MzChA-1, MzChA-2, GBC were cultured as described previously (20) using Dulbecco's modified Eagle's medium (DMEM) supplemented with $10 \%(\mathrm{v} / \mathrm{v})$ fetal bovine serum (FBS; PAA Laboratories, Pasching, Austria) at $37^{\circ} \mathrm{C}$ and
$5 \% \mathrm{CO}_{2}$. Cell lines and human tissue samples are collectively referred to as biliary tract cancer (1) in the following [see (20) for original tumor grading].

Quantitative real-time RT-PCR. For quantification of mRNA levels, cells cultured in $10 \mathrm{~cm}$ diameter Petri dishes were lysed using TRIzol reagent (Invitrogen, Lofer, Austria) and total RNA was isolated according to the manufacturer's instructions. Total RNA was subjected to DNase treatment, reverse transcription and the cDNA was analyzed using quantitative real-time reverse transcription PCR (qRT-PCR) as described previously (20) using a Rotorgene 6000 real-time PCR thermocycler (Qiagen, Hilden, Germany) - see Table IA for primer sequences. The relative expression of each transcript $(\mathrm{X})$ was calculated using the formula $2^{-\Delta \mathrm{Ct}}(21,20)$, in which $\left.\Delta \mathrm{C}_{\mathrm{t}}=\mathrm{C}_{\mathrm{t}(\mathrm{x})}\right)^{-}$ $\mathrm{C}_{\mathrm{t}(\text { housekeeping gene) }}$ with $\beta$-actin as the housekeeping gene (22).

Xenograft model. Cell lines were harvested, resuspended in sterile physiologic $\mathrm{NaCl}$ solution and injected into the flank of 4 to 6 -week old NMRI mice (each $3 \times 10^{6}$ cells per mouse $/ 5$ mice per cell line; Harlan Winkelmann GmbH, Borchen, Germany) $(20,23,24)$. Animals were kept in a light- and temperaturecontrolled environment and provided with food and water ad libitum. Animals were sacrificed at mean day 45 (range 39-46) by cervical dislocation and tumor samples were fixed in $10 \%$ phosphate-buffered formalin. Ethical approval was granted before any animal experiment by the Regional Government of Lower Franconia, Würzburg, Germany (no. 54-2531.31-9/06). 
Table II. Clinical characteristics of human BCT cases (TMA).

\begin{tabular}{|c|c|c|c|c|}
\hline & Overall & Intrahepatic & Perihilar & Extrahepatic \\
\hline $\mathrm{n}(\%)$ & 34 & $20(58.8)$ & $11(32.4)$ & $3(8.8)$ \\
\hline Female & $12(35.2)$ & $7(35)$ & $4(39.4)$ & $1(33.3)$ \\
\hline Male & $22(64.8)$ & $13(65)$ & $7(63.6)$ & $2(67.7)$ \\
\hline Age (mean $\pm \mathrm{SD})$ & $65.9 \pm 12.6$ & $64.7 \pm 13.9$ & $68.2 \pm 10.7$ & $66.8 \pm 13.6$ \\
\hline Female & $65.5 \pm 13.2$ & $65.1 \pm 13.1$ & $64.9 \pm 16.8$ & $70.3^{f}$ \\
\hline Male & $66.1 \pm 12.5$ & $64.4 \pm 14.9$ & $70.1 \pm 6.1$ & $62.6 \pm 15.4$ \\
\hline Growth pattern ${ }^{\mathrm{c}}, \mathrm{m} / \mathrm{p} / \mathrm{i}$ & $18 / 16 / 0$ & $16 / 4 / 0^{\mathrm{b}}$ & $1 / 10 / 0^{\mathrm{b}}$ & $1 / 2 / 0$ \\
\hline G: I / II / III & $2 / 17 / 15$ & $2 / 7 / 11$ & $0 / 8 / 3$ & $0 / 2 / 1$ \\
\hline Size $(\mathrm{cm}$, mean $\pm \mathrm{SD})$ & $3.7 \pm 3.6$ & $5.1 \pm 4.0^{\mathrm{b}}$ & $1.3 \pm 0.7^{\mathrm{b}}$ & $3.1 \pm 1.6$ \\
\hline $\mathrm{T}_{\text {staging }} \mathrm{d}$ & & $\mathrm{p}<0.01$ & $\mathrm{p}<0.01$ & \\
\hline 1 & 13 & 13 & 0 & 0 \\
\hline 2 & 2 & 0 & 0 & 2 \\
\hline $2 a$ & 11 & 6 & 5 & 0 \\
\hline $2 b$ & 5 & 0 & 5 & 0 \\
\hline 3 & 2 & 1 & 0 & 1 \\
\hline 4 & 1 & 0 & 1 & 0 \\
\hline $\mathrm{N}$ staging ${ }^{\mathrm{d}}, 0 / 1$ & $21 / 13$ & $15 / 5^{\mathrm{a} 1}$ & $3 / 8^{\mathrm{a} 1, \mathrm{a} 2}$ & $3 / 0^{\mathrm{a} 2}$ \\
\hline M staging ${ }^{\mathrm{d}}, 0 / 1$ & $26 / 8$ & $16 / 4$ & $8 / 3$ & $2 / 1$ \\
\hline $\mathrm{R}^{\mathrm{d}}: 0 / 1$ & $22 / 12$ & $14 / 6$ & $6 / 5$ & $2 / 1$ \\
\hline Mean survival $[\mathrm{CI}]$ & $11.6[4.5-18.7]$ & $10.8[0.07-21.6]$ & $14.6[4.9-24.3]$ & $7.3[0-19.8]$ \\
\hline Median survival [CI] (months) & $2.1[0-8.3]$ & $2.0[0-4.3]$ & $12.8[0-34.4]$ & $0.9\left[^{\mathrm{g}}\right]$ \\
\hline Therapy $^{\mathrm{e}}, \mathrm{LR} / \mathrm{BT} / \mathrm{WR}$ & $24 / 24 / 4$ & $20 / 10 / 0^{\mathrm{a} 1, \mathrm{a} 2}$ & $4 / 11 / 2^{\mathrm{a} 1}$ & $0 / 3 / 2^{\mathrm{a} 2}$ \\
\hline
\end{tabular}

BT, biliary duct resection; BTC, biliary tract cancer; CI, confidence interval; G, grading; LR, liver resection; R, residual tumor classification (R0/R1); SD, standard deviation; TMA, tissue microarray; WR, whipple resection. ${ }^{a} \mathrm{p}<0.05$; ${ }^{\mathrm{b}} \mathrm{p}<0.01$ (using $\chi^{2}$ test or univariate ANOVA; additional numbers indicate the pair of variables a significant difference exists for); ${ }^{\mathrm{c}} \mathrm{m}$, mass forming; $\mathrm{p}$, periductal; I, intraductal; ${ }^{\mathrm{d} a c c o r d i n g}$ the published TNM [7th edition, 2010 (26)]; ${ }^{\mathrm{e}}$ combination of the surgical interventions could be performed; ${ }^{\mathrm{f}}$ only one case; ${ }^{\mathrm{g}}$ not calculably due to small number of cases.

Tissue preparation and immunochistochemistry. All specimens were fixed in $4 \%$ buffered formalin, routinely processed and embedded in paraffin wax. Immunohistochemistry was done using routine diagnostic methods as published recently (25). In short, immunohistochemical stainings were carried out using an autostainer system (Dako, Vienna, Austria) according to the manufacturer's recommendations. Antigen retrieval was performed by heat induced epitope retrieval in $\mathrm{pH} 9.0$ antigen retrieval buffer (Dako) at $95^{\circ} \mathrm{C}$ for $40 \mathrm{~min}$. Table IB lists the used antibodies, pretreatment conditions and dilutions. Tonsils and lymph nodes served as positive controls; control experiments were negative using PBS replacement of primary or secondary antibodies and same processing as described above (not shown).

Interpretation of immunohistochemistry. The stained slides were digitalized using the ImageAccess 9 Enterprise software (Imagic Bildverarbeitung, Glattbrugg, Switzerland). Images were evaluated using the particle analysis module with optimized binarization method and assessed by two independent investigators (R.K. and D.N.).

Patient characteristics and tissue microarray. Only patients who underwent surgical resection between 1997 and 2010 with complete histopathological records at the Institute of Pathology (Salzburg) were included in the investigations. None of these patients received neoadjuvant therapies. Follow-up data were received from the clinical database and the tumor registry of the Paracelsus Medical University/Salzburger Landeskliniken. Overall, 34 paraffin-embedded tissue samples with primary BTC were included (mean age of $65.90 \pm 12.6$ years, sex: 12 male/22 female) with complete comprehensive clinical information which were subsequently used as covariables (for detail see Table II). All cases were re-classified according the 7th TNM classification of 2010 (26). In contrast to published data (27), cases with intrahepatic BTC $(58.8 \%, \mathrm{n}=20)$ were more frequent in our sample pool. In short, intrahepatic BTC showed preferential mass forming growth pattern and were larger than perihilar BTC, whereas perihilar BTC had a more advanced disease stage according TNM (details see Table II).

Tissue microarrays were prepared from paraffin-embedded tissue blocks. First, we designed a grid using commercial drawing software Microsoft Office 2007 Visio consisting of $2 \mathrm{~mm}$ black circles leaving $2 \mathrm{~mm}$ space between them and printed the grid on plain paper. The grid was fixed to stainless steel moulds and dried cores of paraffin-embedded BTC tissue blocks obtained using a $2 \mathrm{~mm}$ Harris Uni-Core punch (Ted 
A

BMI-1

CD133
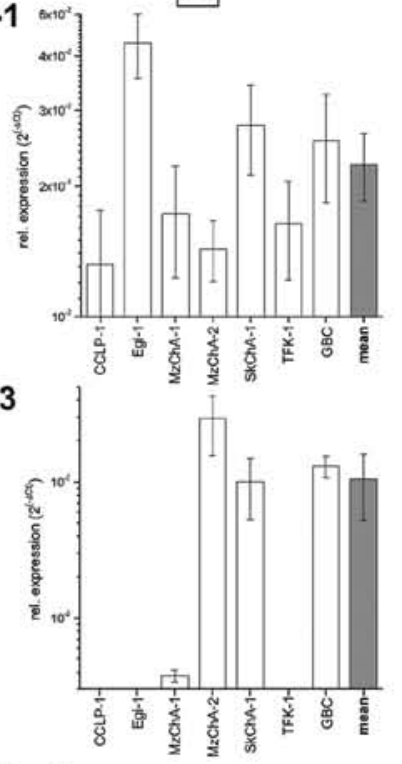

CD44

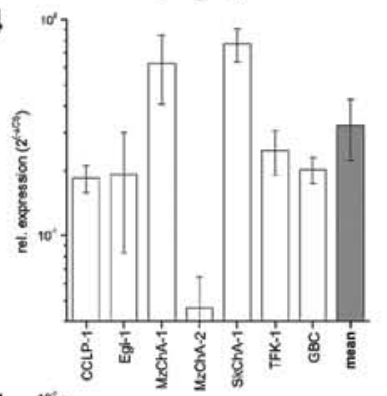

Nanog
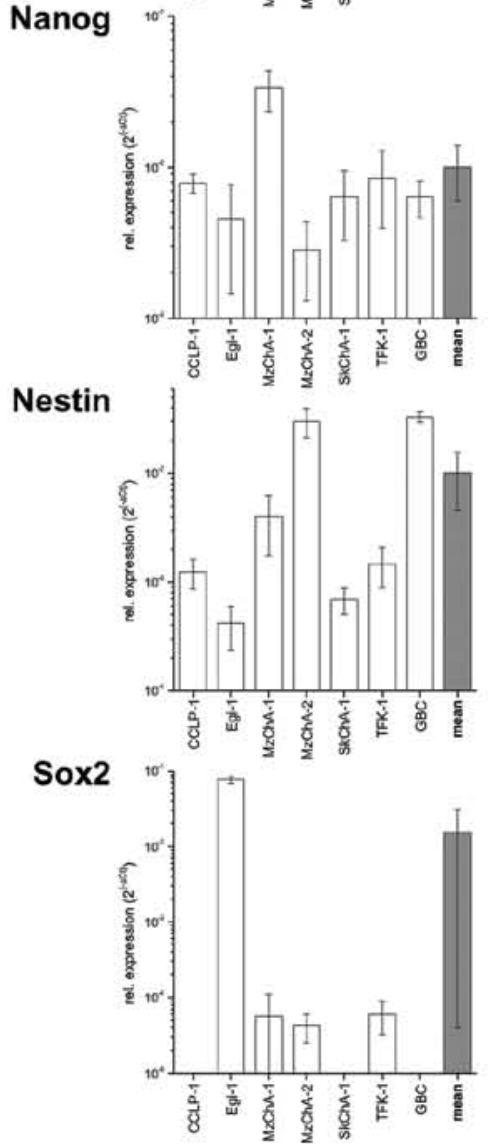

B
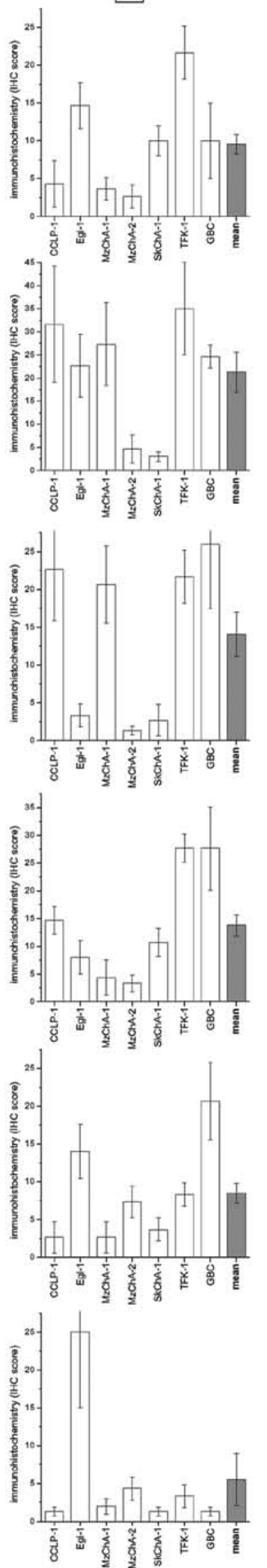

C
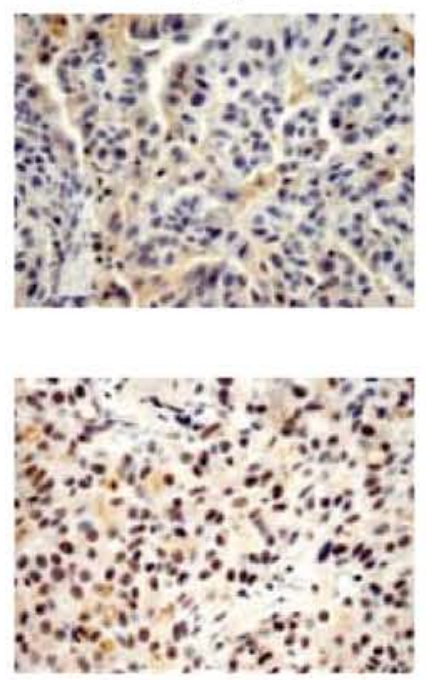

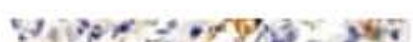
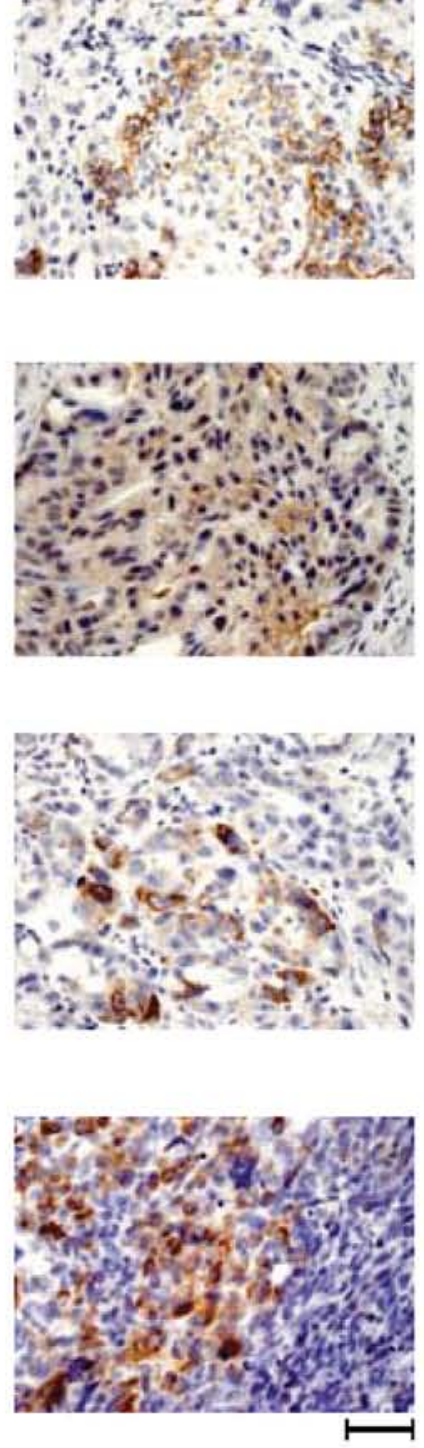

Figure 1. Expression of stem cell marker mRNA/protein in vitro and in vivo. (A) mRNA expression levels were determined by qRT-PCR for each investigated BTC cell line in vitro. (B) Protein expression levels were determined by semi-quantitative immunohistochemistry from in vivo xenograft tumor samples for each investigated BTC cell line. (C) Typical protein expression pattern in BTC xenografts. An example image for each marker is shown; scale bar indicates $50 \mu \mathrm{m}$. 
Pella Inc., Redding, CA, USA) were aligned to the grid. Once all cores were attached to the mould, melted paraffin was gently poured into the mould and the TMA was handled according to routine histopathological procedures from this point on. Additionally, to exclude heterogeneous distribution pattern of the investigated stem cell markers, immunohistochemical staining was performed on tumor center and tumor border areas corresponding to conventional H\&E stained slides.

Ethics. All analyses on human BTC samples were carried out according to the guidelines of the Paracelsus Medical University Salzburg/Salzburger Landeskliniken and were approved by the local ethics committee (415-EP/73/37-2011).

Statistical analysis. Statistical analysis was performed with SPSS 18.0 (SPSS Inc., Chicago, IL, USA). Kendall's rank twotailed test and Spearman rank correlation test was used for the correlation analysis. The $\chi^{2}$ test, Mann-Whitney $U$ test or Student's t-test was used to compare data of nominal, ordinal or interval level, respectively. Univariate ANOVA (analysis of variance) was used to test for differences between groups of tissue samples [using least significant difference (LSD) test post hoc test to adjust for multiple comparisons]. For survival analysis, cases with missing date of death were excluded. Univariate survival analysis was performed using the Kaplan-Meier method comparing the survival curves with the log-rank test. For multivariate survival analysis, the Cox proportional hazards model was used. Differences were considered significant at $\mathrm{p}<0.05$.

\section{Results}

Expression pattern of stem cell markers identify distinct groups of cell lines. The mRNA of all stem cell markers could be detected at low levels throughout all tested human BTC cell lines in vitro, with highest level for CD44 compared to lower levels in all other BTC cell lines, Fig. 1A. The levels of mRNA in vitro mostly correspond to the protein expression levels in vivo (compare Fig. $1 \mathrm{~A}$ and $\mathrm{B}$ ). Generally, the expression data on mRNA and protein levels revealed a heterogeneous pattern with cell lines expressing rather low levels of e.g. CD133 and CD44 (Egi-1, MzCha-2, SkChA-1) compared to the others.

Based on the observed protein expression heterogeneity, hierarchical cluster analysis was used to test whether these patterns could identify distinct subgroups of cells lines. As shown in Fig. 2A, protein expression of CD133 and CD44 classified the cell lines into two groups of which the first group (GBC, MzChA-1, TFK-1 and SkChA-1) is characterized by a CD133 ${ }^{+} / \mathrm{CD}_{4} 4^{+} / \mathrm{Nanog}^{+} / \mathrm{Sox}-2^{-}$expression pattern. The second group (MzChA-2, Egi-1 and CCLP-1) displayed an inverse expression pattern (Fig. 2B). Further comparison between these groups indicated that the first cluster $\left(\mathrm{CD} 133^{+} / \mathrm{CD} 44^{+} / \mathrm{Nanog}^{+} /\right.$ Sox-2') shows decreased proliferation markers (Ki67, cyclin D1) and a higher level of differentiation markers (Ck7, Ck8/18, E-cadherin).

Correlation analysis of stem cell marker expression and differentiation in vitro and in vivo. In the next step, we compared the expression of stem cell markers with those of differentiation in these human BTC cell lines which were comprehensively

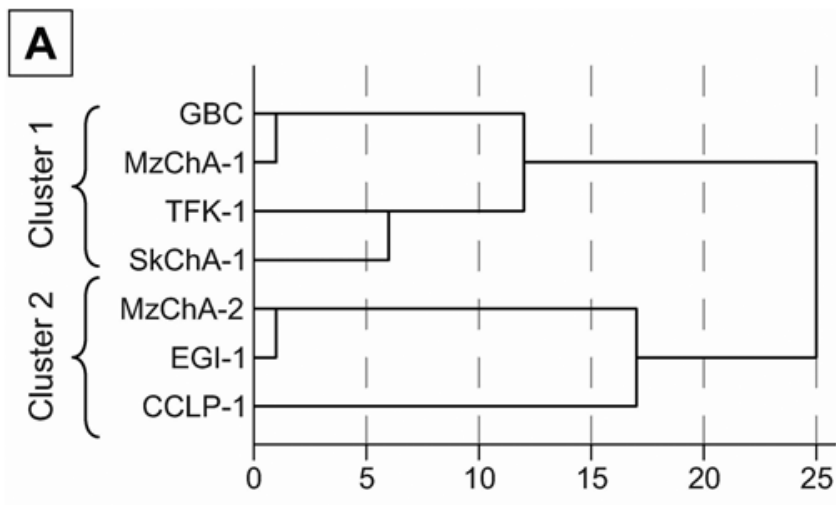

\begin{tabular}{|c|c|c|c|}
\hline $\begin{array}{c}\text { protein levels } \\
\text { [mean } \pm \text { SEM] }\end{array}$ & $\begin{array}{c}\text { Cluster } 1 \\
\text { GBC, MzChA-1, } \\
\text { MzChA-1, TFK-1 }\end{array}$ & $\begin{array}{c}\text { Cluster 2 } \\
\text { CCLP-1, Egi-1, } \\
\text { MzChA-2 }\end{array}$ & \\
\hline CD133 & $29.6 \pm 2.3$ & $10.1 \pm 6.3$ & $\mathrm{p}=0.021^{\star}$ \\
\hline CD44 & $22.7 \pm 1.2$ & $2.4 \pm 0.6$ & $\mathrm{p}<0.001^{\star *}$ \\
\hline Nanog & $18.5 \pm 5.6$ & $7.3 \pm 2.1$ & $p=0.165$ \\
\hline Sox-2 & $2.0 \pm 0.5$ & $10.2 \pm 7.4$ & $p=0.245$ \\
\hline Bmi-1 & $9.9 \pm 4.2$ & $9.1 \pm 3.5$ & $p=0.894$ \\
\hline Nestin & $8.6 \pm 4.2$ & $8.3 \pm 3.0$ & $p=0.996$ \\
\hline & --- & --- & --- \\
\hline Cyclin D1 & $6.6 \pm 0.5$ & $10.7 \pm 0.9$ & $\mathrm{p}=0.009^{* *}$ \\
\hline Ki67 & $7.6 \pm 0.5$ & $8.4 \pm 0.3$ & $p=0.244$ \\
\hline Ck7 & $7.8 \pm 1.8$ & $0.1 \pm 0.1$ & $\mathrm{p}=0.015^{\star}$ \\
\hline Ck8/18 & $11.0 \pm 1.0$ & $5.2 \pm 3.5$ & $p=0.125$ \\
\hline ECad & $8.0 \pm 1.7$ & $3.4 \pm 3.0$ & $p=0.206$ \\
\hline Vim & $0.6 \pm 0.5$ & $5.8 \pm 3.5$ & $p=0.141$ \\
\hline$\alpha 1-\mathrm{ATry}$ & $7.6 \pm 0.7$ & $1.3 \pm 0.5$ & $\mathrm{p}=0.001^{* *}$ \\
\hline CAB & $1.8 \pm 0.3$ & $1.0 \pm 0.0$ & $\mathrm{p}=0.052$ \\
\hline$\beta-\mathrm{Cat}^{\mathrm{mem}}$ & $2.1 \pm 0.8$ & $4.0 \pm 3.5$ & $p=0.559$ \\
\hline$\beta-$ Cat $^{\mathrm{cyt}}$ & $5.0 \pm 1.7$ & $4.4 \pm 1.6$ & $p=0.817$ \\
\hline$\beta-$ Cat $^{\text {nuc }}$ & $0.2 \pm 0.2$ & $1.2 \pm 1.1$ & $p=0.326$ \\
\hline
\end{tabular}

Figure 2. Cluster analysis of BTC xenografts based on stem cell markers (A) Cell lines were clustered using hierarchical cluster analysis based on the IHC protein expression levels of the stem cell markers CD133, CD44, Nestin, Nanog, Sox-2, and Bmi-1. (B) Mean values of stem cell and proliferation or differentiation markers are given as mean \pm SEM. Significant and highly significant differences are marked with ${ }^{*} \mathrm{p}<0.05$ or ${ }^{* *} \mathrm{p}<0.01$, respectively (independent t-test). $\beta$-Cat, $\beta$-catenin; CAB, chromotrope-aniline blue; cyt, cytoplasmatic; ECad, E-cadherin; mem, membranous; nuc, nuclear; Vim, vimentin.

analyzed for immunochemical and histological characteristics in a previous study (20). As shown in Fig. 3, correlation analysis revealed significant association with morphological and molecular markers of proliferation and differentiation as follows: overall, similar correlations are found based on mRNA data (in vitro; Fig. 3A) and protein data sets for these cell lines (in vivo/xenografts; Fig. 3B). As expected from cluster analysis (Fig. 2), the expression of the differentiation markers Ck7 and Ck19 is significantly associated with CD133 and CD44 expression (Fig. 3A and B, respectively). In xenograft tumors, expression of proliferation markers (cyclin D1 and Ki67) are preferentially low in cell lines with high expression of CD44. Interestingly, the expression level of Sox-2 is positively associated with vimentin and nuclear $\beta$-catenin expression, while negatively correlated with the differentiation markers $\mathrm{Ck} 8 / 18$ (not shown) and Ck19. 


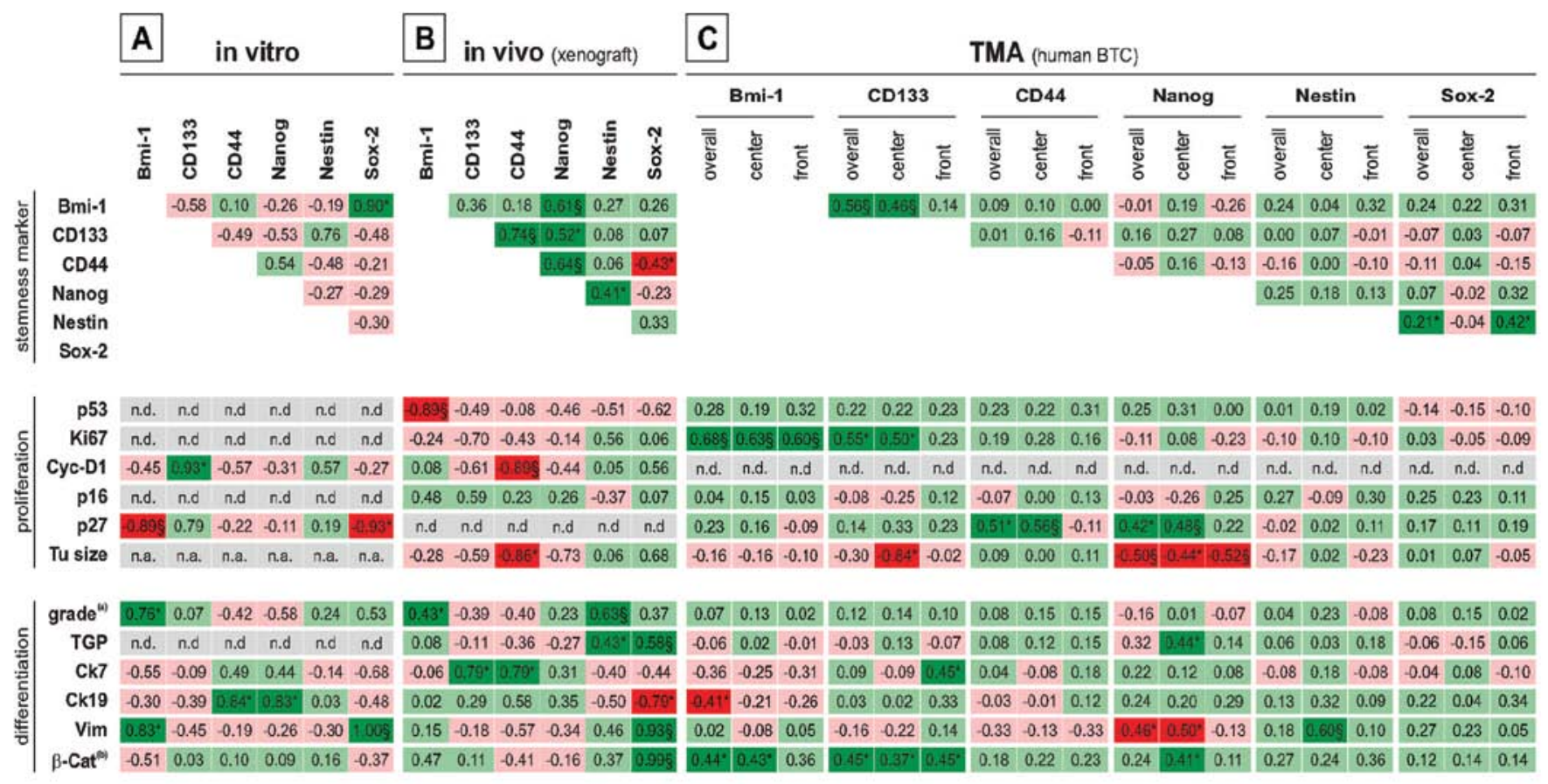

Figure 3. Correlation analysis between stem cell marker, morphological and molecular markers of proliferation and differentiation. Correlations were calculated for mRNA (in vitro) and protein levels [in vivo (xenografts) and human TMAs)] and are given by the Pearson correlation coefficient ${ }^{*} \mathrm{p}<0.05$; ${ }^{\S} \mathrm{p}<0.01$; ${ }^{(\mathrm{a})}$ original tumor grading; ${ }^{(b)}$ nuclear localization. Cyc-D1, cyclin-D1; n.a., not applicable; n.d., not determined; TGP, tumor growth pattern [in vivo: ductal (1), mixed (2), solid (3); TMA: mass forming (1) periductal (2)]; TMA, tissue microarray; Tu, tumor; Vim, Vimentin.

Expression of stemness markers in human BTC. The expression of the mentioned stem cell markers were investigated in human BTC using a tissue microarray consisting of a total of 34 cases including 20 intrahepatic, 11 perihilar, and 3 cases of extrahepatic BTC (see Table II for details). As shown in Fig. 4A, overall protein expression exhibited the highest levels of Nanog followed by CD133 as well as CD44, Bmi-1, Nestin and Sox-2. Fig. 4A also indicates that the expression of these stem cell markers is not dependent on the anatomical location (intra- versus perihilar or extrahepatic), except for Nestin (only perihilar versus extrahepatic). Analysis of stemness marker expression levels depending on the growth type also revealed no significant differences, yet a trend to increased expression of Nanog can be seen for periductal compared to a mass-forming growth type (Fig. 4B). Detailed analysis depending on the intratumoral localization indicated significant higher expression of Bmi-1, CD133 and Nanog in the tumor centers, while Nestin and CD44 are preferentially expressed in the tumor front sections (all $\mathrm{p}<0.05$, paired t-test; Fig. 4C).

Correlation analysis of the marker expression and selected differentiation/proliferation characteristics is shown in Fig. 3C: positive correlation between the proliferation marker Ki67 and stemness marker expression can be found for CD133 and Bmi-1, while CD44 and Nanog expression is associated with high levels of the cell cycle inhibitor p27. Additionally, other cell cycle associated proteins were positively associated with the stemness marker expression. Nuclear $\beta$-catenin is indicative of active Wnt signaling, a signaling pathway implicated in the generation and maintenance of the cancer stem cell population. Interestingly, expression of Bmi-1 CD133 and Nanog in our set of samples is significant positively correlated with nuclear $\beta$-catenin. Interestingly, markers of differentiation (cytokeratins/vimentin) showed no consistent and partially opposite relationship with the stem cell markers. Significant correlation are preferentially found in the tumor center (in detail see Fig. 3C). Based on the findings from xenograft stemness marker expression, the TMA cases were classified using hierarchical cluster analysis based on the marker expression of CD133 and CD44. As shown in Fig. 5A, three distinct clusters could be identified characterized by significant differences in expression of these markers. The marker Bmi-1 showed a significant different expression in the three groups similarly to that of CD133. Interestingly, the proliferation marker Ki67 is significantly higher expressed in the cluster which shows high levels of CD133 and Bmi-1 (Fig. 5B).

Association of stem cell marker expression with clinicopathological data. Using univariate ANOVA (LSD post hoc test), the expression of the investigated stemness markers was compared for different groups of samples stratified either for the different UICC stages, grading, the T-, N-, M-status, growth type and the intra-tumoral localization (see Fig. 6). Here, the analysis revealed only significant different expression of stemness markers for T-status (CD44) and M-status (Nestin) as well as tumor localization (CD133 and Nestin) regarding the tumor subregions (emphasizing predominantly the impact of the tumor front). It is notably that clinicopathological data summarizing different cofactors such as UICC stage (T-, N- and $\mathrm{M}$-status as well as tumor localization) and tumor grading (different morphological aspects) did not reveal a clear dependency of the stemness marker expression pattern. 

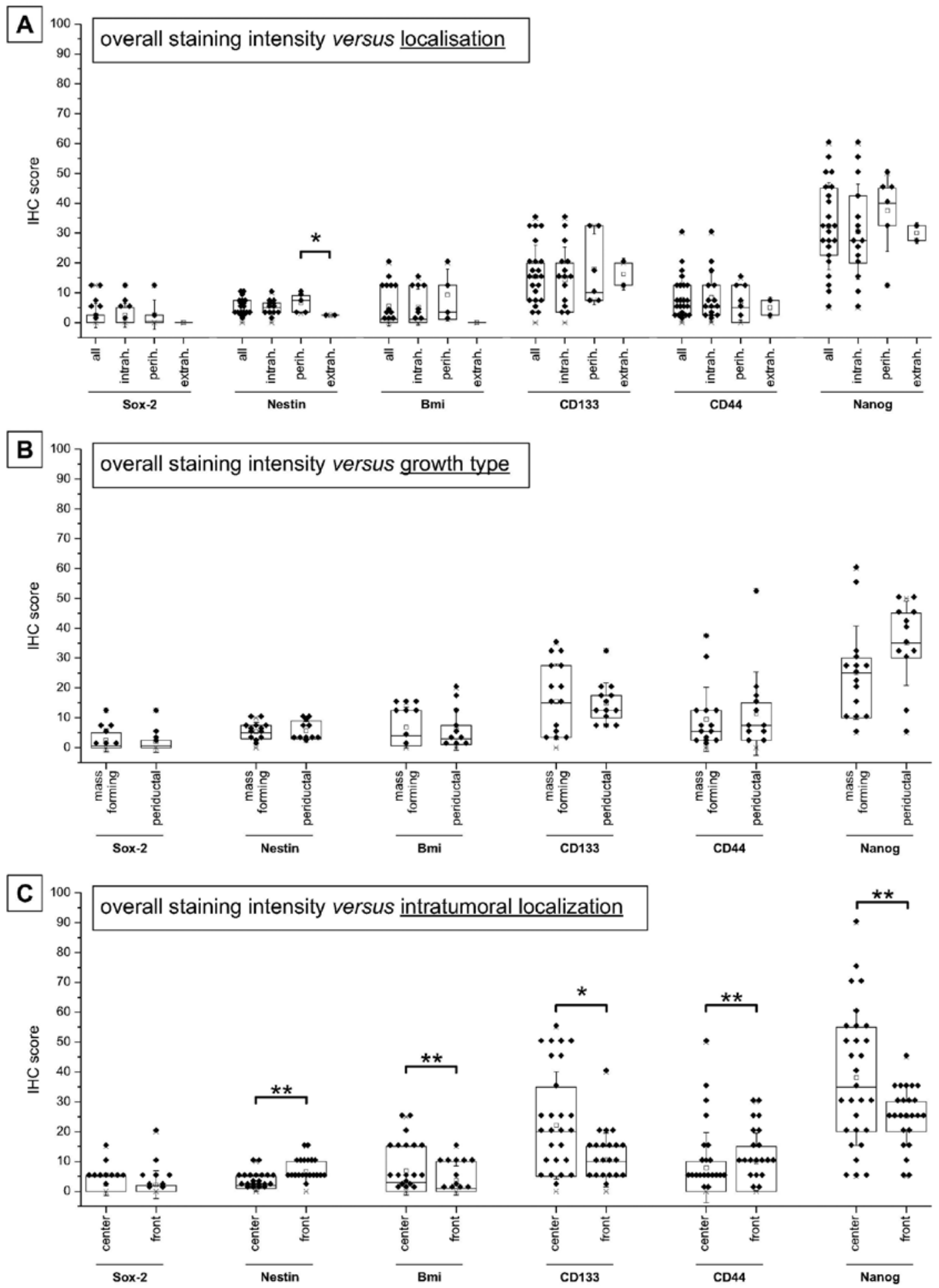

Figure 4. Expression pattern of stem cell markers in a tissue microarray of human BTC. Overall IHC scores (mean \pm SDEV, open symbols) are shown in box plots for (A) the different localizations, (B) different growth types and (C) for the intra-tumoral localization. Significant and highly significant differences between the individual clusters are marked with ${ }^{*} \mathrm{p}<0.05$ or ${ }^{* *} \mathrm{p}<0.01$, respectively [ANOVA, LSD post hoc test (A) and paired t-test (B-C)]. extrahep., extrahepatic; IHC, immunohistochemistry; intrahep., intrahepatic.

Impact of differential stemness marker expression on overall survival. Survival analysis using the Kaplan-Meier method as well as log-rank test showed that patients with mass-forming growth types of BTC have a tendency to poorer survival characteristics compared to those with a periductal growth pattern (Fig. 7A). When patients were stratified for low versus high expression levels of the stemness markers, a clear yet not significant trend of high expression towards shorter survival times could be found for CD133 and CD44 when these markers were used individually (Fig. 7B and C). Combination of all stem cell markers revealed a similar trend of poorer prognosis in patients with tumors of higher marker expression (Fig. 7D) which was statistically significant for the protein expression values ( $p=0.017$, Fig. 7E). 


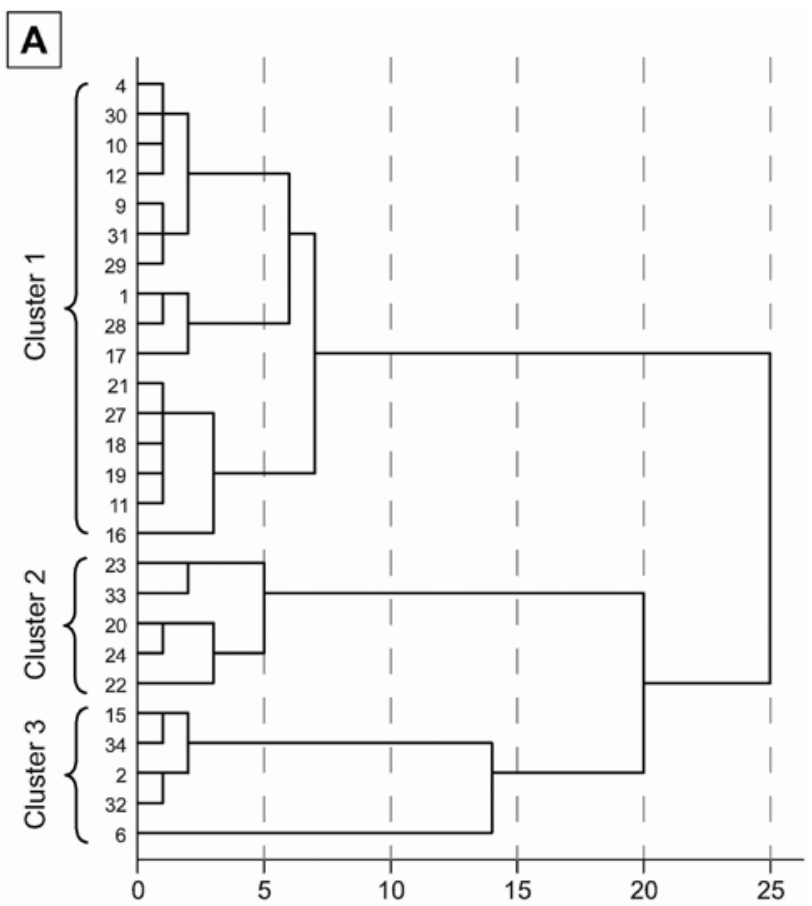

B

\begin{tabular}{|c|c|c|c|}
\hline $\begin{array}{l}\text { rotein levels } \\
\text { eean } \pm \text { SEM] }\end{array}$ & Cluster 2 & Cluster 3 & $\mathrm{p}, \mathrm{ANOVA}$ \\
\hline CD133 & $10.0 \pm 1.4 \ldots 21.0 \pm 1.7 \ldots$ & $32.0 \pm 1.2$ & $p<0.000^{* * *}$ \\
\hline CD44 & $4.8 \pm 0.1 \ldots$ & $5.6 \pm 2.1$ & $p<0.000^{\star *}$ \\
\hline $\begin{array}{l}\text { Nanog } \\
\text { Sox-2 } \\
\text { Bmi-1 }\end{array}$ & $\begin{array}{cc}\mathbf{3 1 . 8} \pm 5.0 & \mathbf{2 8 . 0} \pm 6.3 \\
\mathbf{2 . 3} \pm 1.1 & \mathbf{2 . 0} \pm 1.1 \\
\mathbf{3 . 6} \pm 1.4 & \mathbf{4 . 3} \pm 1.6\end{array}$ & $\begin{array}{c}28.0 \pm 9.0 \\
3.0 \pm 2.4 \\
15.0 \pm 1.4\end{array}$ & $\begin{array}{l}p=0.846 \\
p=0.934 \\
p=0.001^{\text {}}\end{array}$ \\
\hline Nestin & $5.5 \pm 0.7 \quad 4.7 \pm 1.7$ & $6.5 \pm 1.6$ & $p=0.666$ \\
\hline Ki67 & $8.3 \pm 2.0_{\text {ns. }} 13.5 \pm 10.8_{n . \pm}$ & $26.0 \pm 5.3$ & $p=0.016^{\star}$ \\
\hline $\begin{array}{r}\beta-\text { Cat } \\
\text { p53 }\end{array}$ & $\begin{array}{cc}31.1 \pm 6.6 & 30.6 \pm 12.7 \\
9.4 \pm 6.0 & 2.5 \pm 2.5\end{array}$ & $\begin{array}{c}53.5 \pm 7.2 \\
28.5 \pm 11.4\end{array}$ & $\begin{array}{l}p=0.190 \\
p=0.169\end{array}$ \\
\hline
\end{tabular}

Figure 5. Cluster analysis of BTC xenografts based on stem cell markers. (A) BTC samples were clustered using hierarchical cluster analysis based on the IHC protein expression levels of the stem cell markers CD133, CD44, Nestin, Nanog, Sox-2, and Bmi-1. (B) Mean values of stem cell and proliferation or differentiation markers are given as mean \pm SEM. Significant and highly significant differences between the individual clusters are marked with " $\mathrm{p}<0.05$ or ${ }^{* *} \mathrm{p}<0.01$, respectively (ANOVA, LSD post hoc test).

\section{Discussion}

Referring to the recently updated hallmarks of cancer by Hanahan and Weinberg (28) the cancer stem cell model is now accepted as a valid concept of carcinogenesis. This model implies that either a subpopulation of cancer cells acquires a stem cell-like phenotype or dormant tissue stem cells are activated and gain oncogenic properties, associated with enhanced tumorigenic potency of self-renewal, migration and metastatic dissemination. On this background, numerous studies investigated stem cell characteristics in diverse human malignancies giving evidence that most if not all tumors showed a specific stem cell signature (15). Therefore, the current study aimed to investigate the expression of protein markers in human BTC associated with the stemness phenotype and its clinicopathological consequences. In brief, analysis of in vitro samples, xenograft tumor and a human BTC TMA revealed a heterogeneous expression pattern of stemness marker expression. Additionally, survival analyses of these samples indicate a trend to a worse prognosis for cases with higher expression of CD133 and CD44.

In the first part of our investigations we detect all of the employed stem cell markers Bmi-1, Sox-2, Nestin, CD133, CD44 and Nanog showing differential expression pattern in vitro and in vivo, whereby mRNA and protein expression were mostly concordant. Compared to data of stem cell markers in BTC, we confirm the upregulated expression of CD44 and CD133 (17-19,29), but also of the other investigated stemness markers. We expand existing limited data by linking the expression of these stem cell markers with morphology (ductal-solid, positive) and molecular markers of proliferation (negative) and differentiation (dedifferentiation: positive/transdifferentiation negative). As published earlier, dedifferentiation is preferentially linked to stemness characteristics, which can be readily recognized at the level of morphology emphasizing the role of basic histology (30). However, not the hyperproliferative tumor fraction, but rather the resting tumor compartment shows higher expression of these stem cell markers, partly explaining the fact that conventional therapeutic approaches such as chemo- and radiotherapy frequently cannot eradicate the tumor cells completely leading to subsequent recurrence $(29,31)$. Nevertheless, Sasaki et al (32) were able to show that Bmi-1 is expressed in intrahepatic BTC independent of histologic differentiation or location and knockdown of Bmi-1 in BTC cell lines decreased proliferation/colony formation (32). In line with these results, the groups of BTC samples generated by cluster analysis based on CD133 and CD44 marker expression show a concordant expression of Bmi-1 and the proliferation marker Ki-67 (Fig. 5B). Such protein associated subgrouping of primary BTC could be relevant for targeted therapeutic approaches in future (32), as it was shown that expression analysis of nuclear $\beta$-catenin and CD133 in CRC were able to detect high risk cases in patients CRC subgroups of stage IIA for therapeutic decisions (33).

In the second part of our study we investigated the expression pattern of these stem cell markers in a TMA of resected primary BTC. The markers were detected to a heterogeneous extent as seen in the experimental in vitro and in vivo setting, whereby the different levels possibly reflect the influence of the extracellular matrix. Interestingly, we could not detect differences between intrahepatic, perihilar and extrahepatic anatomic location (except for Nestin) as would be expected from studies investigating cell cycle-associated components (34-36). Similarly, a recent publication revealed a significantly different expression of CD133 depending on the tumor growth pattern, but not on intrahepatic and perihilar tumor localization of BTC (37). However, we found a significant preferential localization of CD133, Bmi-1 and Nanog in the tumor center, whereas CD44 and Nestin tend to be expressed in the tumor front. This is in line with earlier findings that intra-tumoral gradients are important for tumorigenesis as well as progression [for review see $(38,39)]$. Experimental investigation revealed that tumor stem cell population is heterogeneous reflecting full morphologic and phenotypic heterogeneity and forcing whole tumor analysis (40). 


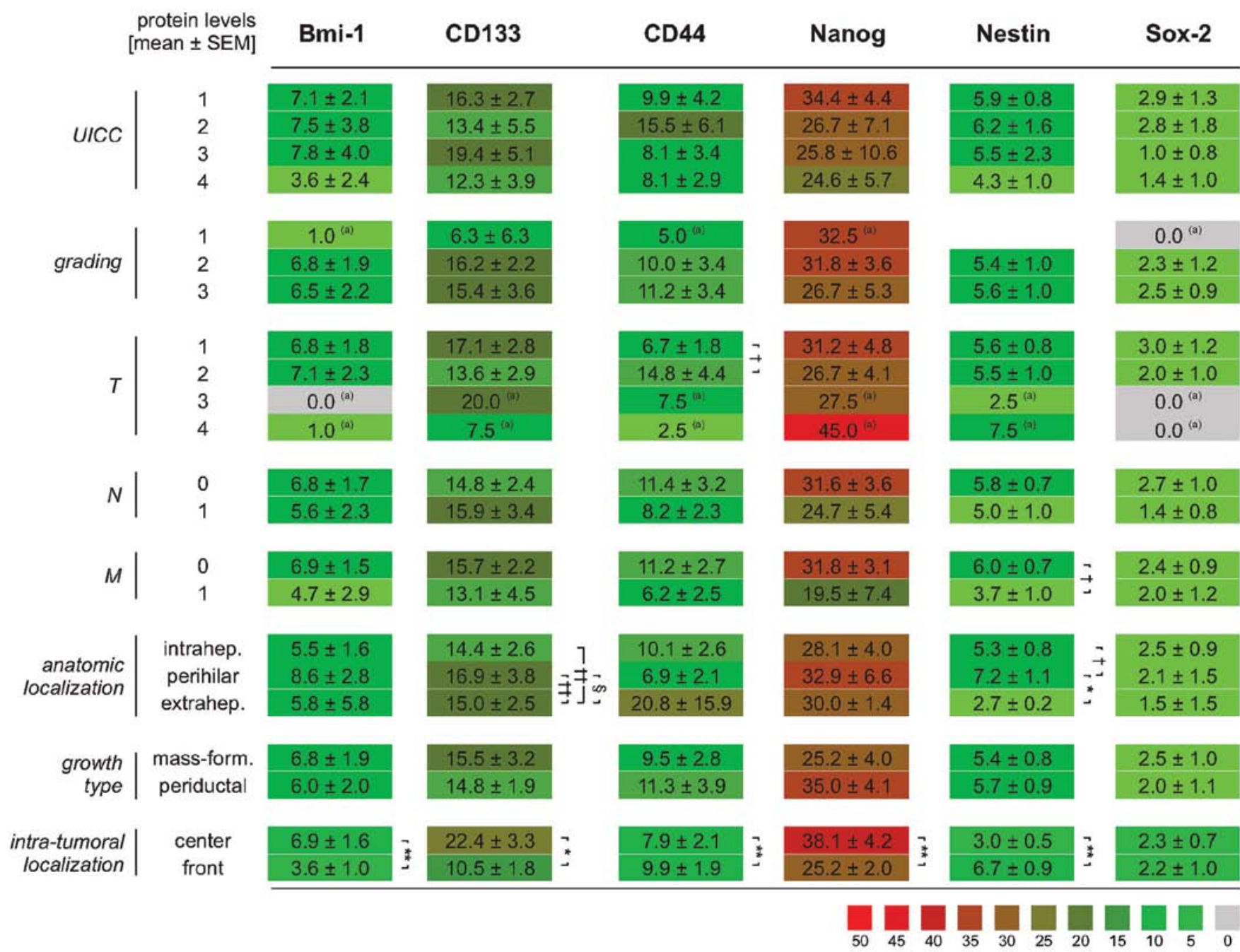

Figure 6. Comparison of stemness marker expression in different sample groups according to clinicopathological parameters. Mean values of stem cell markers are given as mean \pm SEM. ${ }^{(a)}$ Indicates groups with only one case. Significant and highly significant differences between the individual groups are marked with ${ }^{*, 8 .} p<0.05$ or ${ }^{* * \& \$, \dagger} \mathrm{p}<0.01$, respectively (ANOVA, LSD post hoc test) - with ${ }^{*, \$, \dagger}$ stands for overall, tumor center and tumor front, respectively.

In own previous studies, we were able to show that members of the hedgehog pathway as well as markers of cell cycle-associated proteins were topographically differentially distributed in ductal adenocarcinoma of the pancreas (41) reflecting the intratumoral heterogeneity as well as the associated complexity of tumorigenesis. Our findings that not anatomy, but intra-tumor compartments are linked to expression pattern must be seen under the limitation of small number of extrahepatic cases and need confirmation in a larger set of BTC samples.

Interestingly, we found similar correlation of the stem cell markers with markers of differentiation and cell-cycleassociated proteins in the BTC TMA and in our in vitro and in vivo experiments, whereby the in vitro/in vivo situation rather reflects a long-term quiescent than an actively cycling (primed) stem cell as seen in the BTC TMA analysis described $(42,43)$. Moreover, these results do not challenge the indispensable explanatory worth of clinical samples (44) yet they highlight the value of preclinical models as a starting point for investigations as well as models for development of novel therapeutic approaches (45).
In the third part of our study we investigated whether the expression of stem cell markers is linked to clinicopathological data (such as staging, grading and survival). Interestingly, depending on the intra-tumoral localization, only a few stem cell markers (such as CD133, CD44 and Nestin) showed an association with clinicopathological data ( $\mathrm{T}$ and $\mathrm{M}$ status as well as tumor localization) emphasizing the importance to investigate all tumor subregions and indicating that the classical WHO grades for BTC do not reflect the biological and clinical characteristics of BTC. Using Kaplan-Meier survival analyses, high expression of CD133 and CD44 goes along with a non-significant trend to lower overall survival. This result is supported by published data in different human cancers: especially gastric [Sox-2, Oct34 (46,47), Nanog (48), Bmi-1 (49)], colorectal [c-MYC, Sox-2, OCT3/4, LIN28, KLF4, and Nanog (50)], liver [Bmi-1 (51)] and esophageal squamous cell cancer [Oct3/4 and Sox-2 (52)] as well as of human nongastrointestinal cancers \{breast [Sox-2 (53)], lung [Bmi-1 (54)] and brain [Bmi-1 (55)]\}. Additionally, these studies could partially demonstrate an association of stem cell marker 

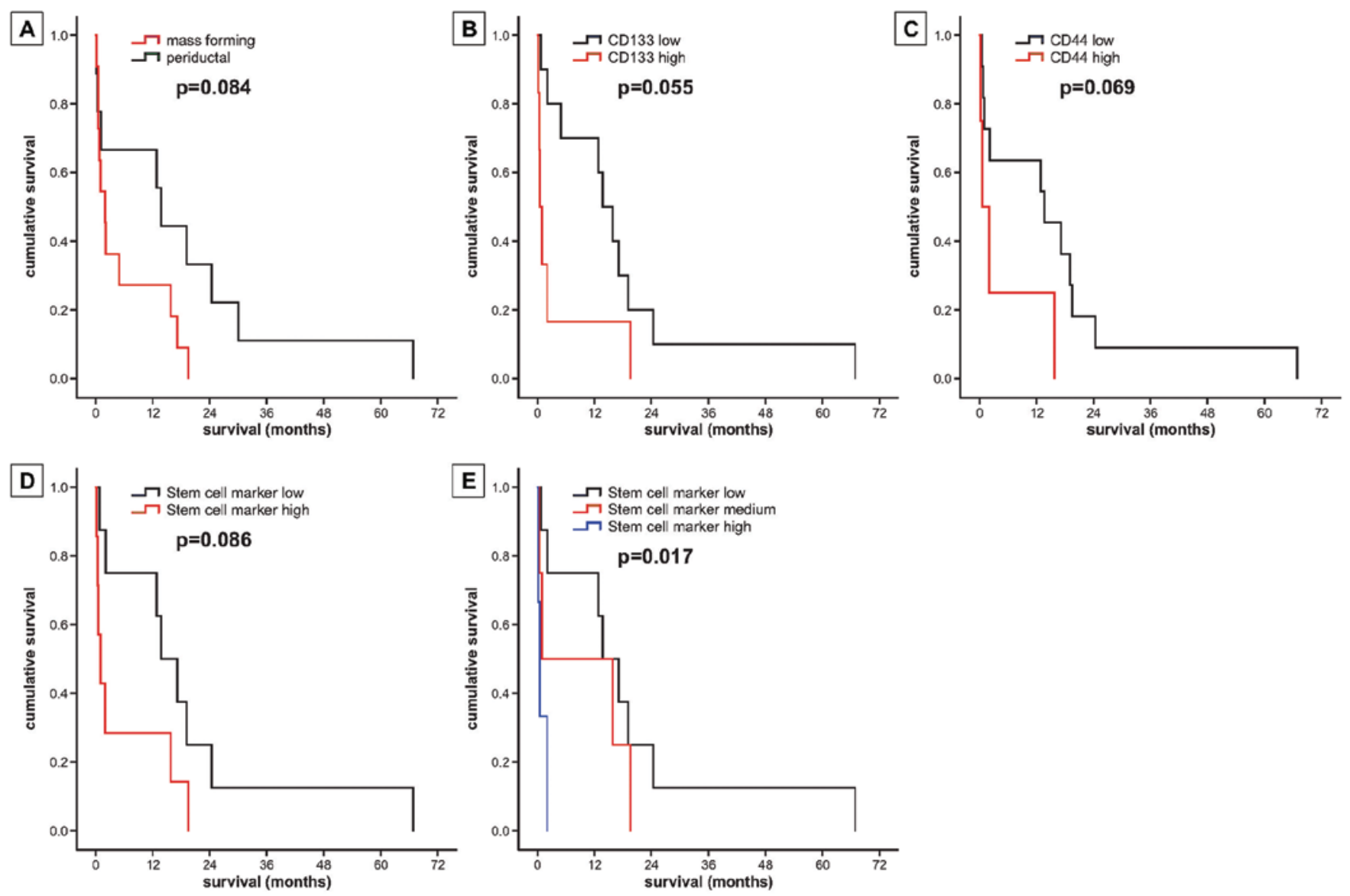

Figure 7. Survival analysis. Kaplan-Meier survival analysis was performed for (A) tumor growth pattern, (B) expression pattern of CD133, (C) CD44 as well as their combination [(D), or addition (E)] in tissue microarray of human BTC. Significant differences in survival were assessed using the log-rank test.

expression with clinical and pathomorphological data such as stage, and lymph node status. Such relationships could not be found in our sample set, possible due to the rather small sample size. Nevertheless, survival analyses showed that, besides tumor growth pattern, the combination of CD133 and CD44 likely is as a prognostic marker significantly associated with worse survival. This is in line with the data of Shimada et al who demonstrated that intrahepatic cholangiocarcinoma expressing the CD133 marker has a significantly worse survival than patients without expression of CD133 (29). The initial isolation and characterization of cancer stem cells in extrahepatic cholangiocarcinoma by Wang et al (18) was based on a marker combination of $\mathrm{CD} 44^{+}$, $\mathrm{CD} 24^{+}, \mathrm{EpCAM}^{\text {high }}$. Cells encompassing this marker phenotype were present in human extrahepatic cholangiocarcinoma to an extent of $0.39-2.27 \%$ and showed high tumorigenic potential in a NOD/SCID mouse model. It remains to be analyzed, whether these markers have a more significant prognostic value than those investigated in the present study. Finally, our findings are supported by recent published investigations on primary cell cultures of gall bladder cancer showing that $\mathrm{CD}_{13} 3^{+}$as well as $\mathrm{CD} 133^{+} / \mathrm{CD} 44^{+}$tumor cell population were more resistant to chemotherapeutic reagents, possessed higher colony-formation ability in vivo and higher tumorigenicity in nude mice than their antigen-negative counterparts $(37,56,57)$.

In conclusion, analysis of expression patterns of putative stem cell markers in vitro and in a xenograft model classified the human BTC into subgroups indicating the heterogeneity of carcinogenesis in BTC. Additionally, the prognostic relevance of the markers identified in this study to significantly impact on overall survival must be proven in further experimental and morphological studies of human tumor specimens of BTC in a larger patient cohort.

\section{Acknowledgements}

The expert technical assistance of Mrs. Berta Lechner is gratefully acknowledged. TK was supported by a research grant of the research fund of the Paracelsus Medical University Salzburg (grant no. R-10/04/17-KIE).

\section{References}

1. de Groen PC, Gores GJ, LaRusso NF, Gunderson LL and Nagorney DM: Biliary tract cancers. N Engl J Med 341: 1368-1378, 1999.

2. Aljiffry M, Abdulelah A, Walsh M, Peltekian K, Alwayn I and Molinari M: Evidence-based approach to cholangiocarcinoma: a systematic review of the current literature. J Am Coll Surg 208: 134-147, 2009.

3. Zografos GN, Farfaras A, Zagouri F, Chrysikos D and Karaliotas K: Cholangiocarcinoma: principles and current trends. Hepatobiliary Pancreat Dis Int 10: 10-20, 2011.

4. Kiesslich T, Wolkersdorfer G, Neureiter D, Salmhofer H and Berr F: Photodynamic therapy for non-resectable perihilar cholangiocarcinoma. Photochem Photobiol Sci 8: 23-30, 2009. 
5. Verslype C, Prenen $\mathrm{H}$ and Van Cutsem E: The role of chemotherapy in biliary tract carcinoma. HPB (Oxford) 10: 164-167, 2008

6. Bailey JM, Singh PK and Hollingsworth MA: Cancer metastasis facilitated by developmental pathways: Sonic hedgehog, Notch, and bone morphogenic proteins. J Cell Biochem 102: 829-839, 2007

7. Fava G, Marzioni M, Benedetti A, Glaser S, DeMorrow S, Francis $\mathrm{H}$ and Alpini G: Molecular pathology of biliary tract cancers. Cancer Lett 250: 155-167, 2007.

8. Wiedmann MW and Mossner J: Molecular targeted therapy of biliary tract cancer - results of the first clinical studies. Curr Drug Targets 11: 834-850, 2010.

9. Neureiter D, Herold C and Ocker M: Gastrointestinal cancer only a deregulation of stem cell differentiation? (Review). Int J Mol Med: 483-489, 2006.

10. Brabletz T, Jung A, Spaderna S, Hlubek F and Kirchner T: Opinion: migrating cancer stem cells - an integrated concept of malignant tumour progression. Nat Rev Cancer 5: 744-749, 2005.

11. Brabletz S, Schmalhofer O and Brabletz T: Gastrointestinal stem cells in development and cancer. J Pathol 217: 307-317, 2009.

12. Jopling C, Boue $\mathrm{S}$ and Izpisua Belmonte JC: Dedifferentiation, transdifferentiation and reprogramming: three routes to regeneration. Nat Rev Mol Cell Biol 12: 79-89, 2011

13. Al Hajj M, Wicha MS, Benito-Hernandez A, Morrison SJ and Clarke MF: Prospective identification of tumorigenic breast cancer cells. Proc Natl Acad Sci USA 100: 3983-3988, 2003.

14. Todaro M, Francipane MG, Medema JP and Stassi G: Colon cancer stem cells: promise of targeted therapy. Gastroenterology 138: 2151-2162, 2010

15. Alison MR, Lim SM and Nicholson LJ: Cancer stem cells: problems for therapy? J Pathol 223: 147-161, 2011.

16. Horst D, Kriegl L, Engel J, Kirchner T and Jung A: Prognostic significance of the cancer stem cell markers CD133, CD44, and CD166 in colorectal cancer. Cancer Invest 27: 844-850, 2009.

17. Shimada M, Sugimoto K, Iwahashi S, Utsunomiya T, Morine Y, Imura $\mathrm{S}$ and Ikemoto T: CD133 expression is a potential prognostic indicator in intrahepatic cholangiocarcinoma. J Gastroenterol 45: 896-902, 2010.

18. Wang M, Xiao J, Shen M, et al: Isolation and characterization of tumorigenic extrahepatic cholangiocarcinoma cells with stem cell-like properties. Int J Cancer 128: 72-81, 2011.

19. Nagai K, Ishii H, Miyoshi N, et al: Long-term culture following ES-like gene-induced reprogramming elicits an aggressive phenotype in mutated cholangiocellular carcinoma cells Biochem Biophys Res Commun 395: 258-263, 2010.

20. Kiesslich T, Alinger B, Wolkersdorfer GW, Ocker M Neureiter D and Berr F: Active Wnt signalling is associated with low differentiation and high proliferation in human biliary tract cancer in vitro and in vivo and is sensitive to pharmacological inhibition. Int J Oncol 36: 49-58, 2010.

21. Berman DM, Karhadkar SS, Maitra A, et al: Widespread requirement for Hedgehog ligand stimulation in growth of digestive tract tumours. Nature 425: 846-851, 2003.

22. Radonic A, Thulke S, Mackay IM, Landt O, Siegert W and Nitsche A: Guideline to reference gene selection for quantitative real-time PCR. Biochem Biophys Res Commun 313: 856-862, 2004.

23. Neureiter D, Zopf S, Dimmler A, et al: Different capabilities of morphological pattern formation and its association with the expression of differentiation markers in a xenograft model of human pancreatic cancer cell lines. Pancreatology 5: 387-397, 2005.

24. Zopf S, Neureiter D, Bouralexis S, et al: Differential response of p53 and p21 on HDAC inhibitor-mediated apoptosis in HCT116 colon cancer cells in vitro and in vivo. Int J Oncol 31: 1391-1402, 2007.

25. Kemmerling R, Stintzing S, Muhlmann J, Dietze O and Neureiter D: Primary testicular lymphoma: A strictly homogeneous hematological disease? Oncol Rep 23: 1261-1267, 2010 .

26. Tannapfel A and Wittekind C: The current TNM system for gastrointestinal tumors part II. Pathologe 31: 348-352, 2010 (In German).

27. Malhi H and Gores GJ: Cholangiocarcinoma: modern advances in understanding a deadly old disease. J Hepatol 45: 856-867, 2006.

28. Hanahan D and Weinberg RA: Hallmarks of cancer: the next generation. Cell 144: 646-674, 2011.
29. Shimada M, Sugimoto K, Iwahashi S, Utsunomiya T, Morine Y, Imura $\mathrm{S}$ and Ikemoto T: CD133 expression is a potential prognostic indicator in intrahepatic cholangiocarcinoma. J Gastroenterol 45: 896-902, 2010.

30. Zhang C, Fu X, Chen P, et al: Dedifferentiation derived cells exhibit phenotypic and functional characteristics of epidermal stem cells. J Cell Mol Med 14: 1135-1145, 2010.

31. Singh A and Settleman J: EMT, cancer stem cells and drug resistance: an emerging axis of evil in the war on cancer. Oncogene 29: 4741-4751, 2010

32. Sasaki M, Yamaguchi J, Ikeda H, Itatsu K and Nakanuma Y: Polycomb group protein Bmil is overexpressed and essential in anchorage-independent colony formation, cell proliferation and repression of cellular senescence in cholangiocarcinoma: tissue and culture studies. Hum Pathol 40: 1723-1730, 2009.

33. Horst D, Kriegl L, Engel J, Jung A and Kirchner T: CD133 and nuclear beta-catenin: the marker combination to detect high risk cases of low stage colorectal cancer. Eur J Cancer 45: 2034-2040, 2009

34. Miller G, Socci ND, Dhall D, et al: Genome wide analysis and clinical correlation of chromosomal and transcriptional mutations in cancers of the biliary tract. J Exp Clin Cancer Res 28: 62, 2009

35. Jarnagin WR, Klimstra DS, Hezel M, et al: Differential cell cycle-regulatory protein expression in biliary tract adenocarcinoma: correlation with anatomic site, pathologic variables, and clinical outcome. J Clin Oncol 24: 1152-1160, 2006.

36. Karamitopoulou E, Tornillo L, Zlobec I, et al: Clinical significance of cell cycle- and apoptosis-related markers in biliary tract cancer: a tissue microarray-based approach revealing a distinctive immunophenotype for intrahepatic and extrahepatic cholangiocarcinomas. Am J Clin Pathol 130: 780-786, 2008.

37. Ohtsubo I, Ajiki T, Hori Y, et al: Distinctive expression of CD133 between intraductal papillary neoplasms of the bile duct and bile duct adenocarcinomas. Hepatol Res: Jan 6, 2012 (Epub ahead of print).

38. Hanahan D and Folkman J: Patterns and emerging mechanisms of the angiogenic switch during tumorigenesis. Cell 86: 353-364, 1996.

39. Kiesslich T, Berr F, Alinger B, Kemmerling R, Pichler M, Ocker $\mathrm{M}$ and Neureiter D: Current status of therapeutic targeting of developmental signalling pathways in oncology. Curr Pharm Biotechnol: May 24, 2011 (Epub ahead of print).

40. Dalerba P, Dylla SJ, Park IK, et al: Phenotypic characterization of human colorectal cancer stem cells. Proc Natl Acad Sci USA 104: 10158-10163, 2007.

41. Quint K, Stintzing S, Alinger B, et al: The expression pattern of PDX-1, SHH, patched and Gli-1 is associated with pathological and clinical features in human pancreatic cancer. Pancreatology 9: 116-126, 2009.

42. $\mathrm{Li} \mathrm{L}$ and Clevers $\mathrm{H}$ : Coexistence of quiescent and active adult stem cells in mammals. Science 327: 542-545, 2010.

43. Scoville DH, Sato T, He XC and Li L: Current view: intestinal stem cells and signaling. Gastroenterology 134: 849-864, 2008.

44. Gillet JP, Calcagno AM, Varma S, et al: Redefining the relevance of established cancer cell lines to the study of mechanisms of clinical anti-cancer drug resistance. Proc Natl Acad Sci USA 108: 18708-18713, 2011.

45. Kiesslich T and Neureiter D: Editorial: Advances in targeting the hedgehog signaling pathwy in cancer therapy. Expert Opin Ther Targets 16: 151-156, 2012.

46. Matsuoka J, Yashiro M, Sakurai K, et al: Role of the stemness factors Sox 2, Oct $3 / 4$, and Nanog in gastric carcinoma. J Surg Res: 130-135, 2012.

47. Zhang X, Yu H, Yang Y, et al: SOX2 in gastric carcinoma, but not Hath1, is related to patients' clinicopathological features and prognosis. J Gastrointest Surg 14: 1220-1226, 2010.

48. Lin T, Ding YQ and Li JM: Overexpression of Nanog protein is associated with poor prognosis in gastric adenocarcinoma. Med Oncol: Feb 20, 2011 (Epub ahead of print).

49. Liu JH, Song LB, Zhang X, et al: Bmi-1 expression predicts prognosis for patients with gastric carcinoma. J Surg Oncol 97: 267-272, 2008

50. Saiki Y, Ishimaru S, Mimori K, et al: Comprehensive analysis of the clinical significance of inducing pluripotent stemnessrelated gene expression in colorectal cancer cells. Ann Surg Oncol 16: 2638-2644, 2009.

51. Wang H, Pan K, Zhang HK, et al: Increased polycomb-group oncogene Bmi-1 expression correlates with poor prognosis in hepatocellular carcinoma. J Cancer Res Clin Oncol 134 535-541, 2008 
52. Wang Q, He W, Lu C, et al: Oct3/4 and Sox 2 are significantly associated with an unfavorable clinical outcome in human esophageal squamous cell carcinoma. Anticancer Res 29: 1233-1241, 2009.

53. Lengerke C,Fehm T, Kurth R, et al: Expression of the embryonic stem cell marker SOX2 in early-stage breast carcinoma. BMC Cancer 11: 42, 2011.

54. Vrzalikova K, Skarda J, Ehrmann J, et al: Prognostic value of Bmi-1 oncoprotein expression in NSCLC patients: a tissue microarray study. J Cancer Res Clin Oncol 134: 1037-1042, 2008.
55. Hayry V, Tynninen O, Haapasalo HK, et al: Stem cell protein BMI-1 is an independent marker for poor prognosis in oligodendroglial tumours. Neuropathol Appl Neurobiol 34: 555-563, 2008.

56. Shi CJ, Gao J, Wang M, et al: CD133(+) gallbladder carcinoma cells exhibit self-renewal ability and tumorigenicity. World J Gastroenterol 17: 2965-2971, 2011.

57. Shi C, Tian R, Wang M, et al: $\mathrm{CD}_{4} 4^{+} \mathrm{CD} 133^{+}$population exhibits cancer stem cell-like characteristics in human gallbladder carcinoma. Cancer Biol Ther 10: 1182-1190, 2010. 